\title{
Abstract Anaphora Resolution in Danish
}

\author{
Costanza Navarretta \\ Center for Sprogteknologi \\ Njalsgade 80 \\ 2300 København S \\ costanza@cst.ku.dk
}

\begin{abstract}
In this paper ${ }^{1}$ I describe the use of Danish pronouns and deictics in dialogues. Then I present an adaptation to Danish of Eckert and Strube's algorithm for resolving anaphora referring to individual NPs and abstract objects in English dialogues (Eckert and Strube, 1999b; Eckert and Strube, 1999a). The adapted algorithm is tested on four Danish dialogues from two dialogue collections and the results obtained are evaluated.
\end{abstract}

\section{Introduction}

Many natural language processing applications involve the complex task of resolving anaphora. Different strategies for anaphora resolution have been proposed, some exclusively relying on the syntactic structure of discourse, some including semantic and pragmatic constraints, some based on statistical methods. One of the most popular approaches to anaphora resolution is centering (Grosz et al., 1995), henceforth GJW95, which accounts for the relation between the saliency of entities in discourse and the use of referring expressions, incorporating syntax, semantics and pragmatics. Centering fits into Grosz and Sidner's model of discourse structure (Grosz and Sidner, 1986). In this model a discourse is composed of segments which exhibit global coherence. A discourse

\footnotetext{
${ }^{1}$ This work has been carried out under Staging, an on-going Danish project funded by the Danish Research Councils.
}

segment, on the other hand, is composed of a sequence of utterances which exhibit local coherence. This latter phenomenon is accounted for by centering theory. Centering predicts that there is a connection between the coherence of a referring expression and the inference load necessary to resolve it. Although Grosz, Joshi and Weinstein recognize that many factors determine the prominence of entities in an utterance, in GJW95 this prominence is established simply by the linear order of the entities in the utterance. Different centering algorithms have been presented, spelling out the strategy described in GJW95, extending the theory to more linguistic phenomena or specifying the concept of prominence of discourse entities. Strube and Hahn (Strube, 1998; Strube and Hahn, 1999) in particular, calculate prominence considering the information structure of the utterances (functional centering). ${ }^{2}$ The prominence ranking they adopt does not exclusively rely on word order, which is language dependent. Moreover GJW95 only dealt with intersentential anaphora, while Strube and Hahn account for both intrasentential and intersentential, pronominal and nominal anaphora. ${ }^{3}$

Centering-based algorithms have been tested on written texts. Recently they have also been applied to written dialogues. Byron and Stent (1998), in particular, test centering on multi-party dialogues. They conclude that centering seems to be a valid theory also in this case, but it must be extended to ac-

\footnotetext{
${ }^{2}$ In (Strube and Hahn, 1996) a functional-based prominence ranking has been proposed.

${ }^{3} \mathrm{An}$ other extension of the centering framework to intrasentential anaphora has been proposed by Kameyama (1998).
} 
count for dialogue-specific aspects such as the definition of utterance boundaries, the specification of a strategy for tackling partial utterances and including discourse participants in the list of relevant discourse entities.

Eckert and Strube (1999a; 1999b), henceforth ES99, describe an algorithm for resolving anaphors referring to individual NPs and abstract objects in English dialogues. The algorithm is based on rules for discriminating among the two types of anaphor based on the predicative contexts in which the anaphors occur. The individual anaphors are then resolved by the functional centering algorithm described in (Strube, 1998), while abstract anaphors are resolved with a different algorithm. ES99 test the approach on selected dialogues and obtain a precision of $63,6 \%$ for discourse deictics and $66,2 \%$ for individual anaphors. They report that most errors are due to the inability to distinguish between discourse deictics and pronouns which vaguely refer to concepts in the preceding discourse (vague anaphors). Another cause of error is the lack of information about abstract nominals. I believe that the strategy followed by ES99 is a good starting point for investigating how far one can go in resolving individual and abstract anaphors in dialogues on the basis of the local contexts in which the anaphors occur. I have adapted the algorithm so it accounts for Danish data and have applied it to Danish dialogues. ${ }^{4}$

In section 2 I shortly present the original centering framework and functional centering as described in (Strube, 1998), S98. In section 3 Eckert and Strube's algorithm is introduced and in 4 the Danish personal and demonstrative pronouns are described with focus on discourse deictics in dialogues. In section 5 I present my adaptation of the ES99algorithm to Danish data. Section 6 contains an evaluation of the results obtained by manually testing the adapted ES99-algorithm on randomly selected dialogues from the collection "Samtale hos Lægen" (Conversation at the doctor's) (SL) and "ProjektIndvandr-

\footnotetext{
${ }^{4}$ Centering-based algorithms have recently been tested on Danish discourse (Navarretta, 2000).
}

erdansk" (Project Immigrant Danish) (PID), collected by researchers at the Department of General and Applied Linguistics of the University of Copenhagen. In section 7 I outline future work for improving the results of the algorithm and make some concluding remarks.

\section{Centering}

In GJW95 the entities which link an utterance $U_{n}$ to the others in the same discourse segment are the centers of that utterance. Each utterance is assigned a set of forward-looking centers, $C_{f}$, and, with the exception of the initial utterance of the segment, a backwardlooking center, $C_{b}$. The $C_{b}$ of an utterance $U_{n}$ connects with one of the forward-looking centers of the preceding utterance $U_{n-1}$ while the forward-looking centers only depend on the expressions in $U_{n}$. The forward-looking centers are partially ordered to reflect relative prominence. GJW95 recognize three types of transition relation across pairs of utterances: continue, retain and shift (see table 1).

Center movement and realization are constrained by two rules:

Rule 1: If any element of $C_{f}\left(U_{n-1}\right)$ is realized by a pronoun in $U_{n}$, then $C_{b}\left(U_{n}\right)$ must also be realized by a pronoun

Rule 2: Center continuation is preferred to center retaining which is preferred to center shifting

\subsection{Functional Centering}

In S98 the functions of the backward-looking center and the transitions in the centering theory are replaced by the order of elements in a list of salient discourse entities, the $\mathbf{S}$ list. The ranking criteria for the elements in the S-list are based on (Prince, 1981), where discourse entities are classified into hearerold (OLD), mediated (MED) and hearer-new (NEW). The two tuples $\left(x, u t t_{x}, p o s_{x}\right)$ and $\left(y, u t t_{y}, \operatorname{pos}_{y}\right)$ in the S-list indicate that the entity $x$ is evoked in utterance $u t t_{x}$ at position $\operatorname{pos}_{x}$ and that $y$ is evoked in utterance $u t t_{y}$ at position pos $_{y}$ respectively. Given that $u t t_{x}$ and $u t t_{y}$ refer to $U_{n}$ or $U_{n-1}$, the follow- 
Table 1: Transition States

\begin{tabular}{|c|c|c|}
\hline & $\begin{array}{c}C_{b}\left(U_{n}\right)=C_{b}\left(U_{n-1}\right) \\
\text { OR no } C_{b}\left(U_{n-1}\right)\end{array}$ & $C_{b}\left(U_{n}\right) \neq C_{b}\left(U_{n-1}\right)$ \\
\hline $\begin{array}{c}C_{b}\left(U_{n}\right)= \\
C_{p}\left(U_{n}\right)\end{array}$ & CONTINUE & \\
\hline $\begin{array}{c}C_{b}\left(U_{n}\right) \neq \\
C_{p}\left(U_{n}\right)\end{array}$ & RETAIN & \\
\hline
\end{tabular}

ing ranking constraints on the S-list entities are valid (Strube, 1998)[p.1253]: ${ }^{5}$

1. if $x \in$ OLD and $y \in \mathrm{MED}$, then $x \prec y$ if $x \in$ OLD and $y \in \mathrm{NEW}$, then $x \prec y$ if $x \in \mathrm{MED}$ and $y \in \mathrm{NEW}$, then $x \prec y$

2. if $x, y \in$ OLD or $x, y \in$ MED or $x, y \in$ NEW,

then if $u t t_{x}>u t t_{y}$ then $x \prec y$

if $u t t_{x}=u t t_{y}$ and $\operatorname{pos}_{x}<\operatorname{pos}_{y}$ then $x \prec y$

The S98-algorithm consists in testing a referring expression against the elements in the S-list from left to right until the test succeeds. The S-list is then updated so that new elements are inserted according to the S-list ranking criteria. When the analysis of an utterance is finished all the entities which were not realized in the utterance are removed from the S-list.

\section{Eckert and Strube's Algorithm}

ES99 propose a new algorithm for resolving anaphors with abstract object antecedents. Analyzing a collection of telephone conversations they distinguish the following anaphor types: individual anaphors, discourse deictics, inferrable-evoked anaphors ${ }^{6}$ and vague anaphors. Other types of pronoun are not taken into consideration.

Predicates that are preferentially associated with abstract objects are marked as Iincompatible $(* I)$ while predicates that are preferentially associated with individual objects are marked as A-incompatible $\left({ }^{*} \mathbf{A}\right)$.

\footnotetext{
${ }^{5}$ I mark ranking precedence with $\prec$.

${ }^{6}$ Inferrable-evoked anaphors refer to the use of the plural pronoun they indirectly co-specifying with a singular NP which indicates a country or an institution.
}

ES99 define the following ${ }^{*}$ I predicates (Eckert and Strube, 1999b)[p. 40]:

- Equating constructions where a pronominal referent is equated with an abstract object, e.g., $x$ is making it easy, $x$ is a suggestion.

- Copula constructions whose adjectives can only be applied to abstract entities, e.g., $x$ is true, $x$ is false, $x$ is correct, $x$ is right, $x$ isn't right.

- Arguments of verbs describing propositional attitude which take S'-complements, e.g., assume.

- Object of $d o$.

- Predicate or anaphoric referent is a "reason", e.g., $x$ is because I like her, $x$ is why he's late.

Predicates that are preferentially associated with individual objects are the following (Eckert and Strube, 1999b)[p. 40]:

- Equating constructions where a pronominal referent is equated with a concrete individual referent, e.g., $x$ is a car.

- Copula constructions with adjectives which can only be applied to concrete entities, e.g., $x$ is expensive, $x$ is tasty, $x$ is loud.

- Arguments of verbs describing physical contact/stimulation, which cannot be used anaphorically, e.g., break $x$, smash $x$, eat $x$, drink $x$, smell $x$ but NOT *see $x$

Grounded acts are used as domain for the anaphor resolution algorithms in dialogues. 
In particular two dialogue acts, Initiations (Is) and Acknowledgments (As) are recognized. Is have semantic content, while As are only used to ground the preceding $I$. Acknowledgments/Initiations (A/Is) are dialogue acts that have both the function of grounding the preceding $I$ and that of establishing a new I. An I and the corresponding $\mathbf{A}$, together with longer $\mathbf{I s}$ in the same turn-taking which do not need to be acknowledged, constitute a Synchronizing Unit (SU). Short Is which are not acknowledged are ignored by the resolution algorithms.

ES99 follow i.a. (Webber, 1991) in assuming that anaphoric discourse deictic reference involves reference coercion and that only discourse sections adjacent to the anaphor or, using Webber's terminology, sections on the right frontier of the discourse structure tree, are available for discourse-deictic reference. Like (Asher, 1993) they assume that the type of abstract object is determined by the context in which the anaphor occurs. Anaphora referring to abstract objects are resolved using a list, the A-list. The A-list is only filled when discourse deictics occur and its elements remain for one $I$. The parts of the linguistic contexts are accessed in the following order: 1. the A-list; 2 . in the same I the clause to the left of the clause which contains the anaphor; 3. within the previous $I$ the rightmost main clause and subordinated clauses to its right; 4. within previous Is the rightmost complete sentence, if previous $I$ is an incomplete sentence.

The anaphora resolution algorithm for third person singular neuter personal pronouns is the following (Eckert and Strube, 1999a):

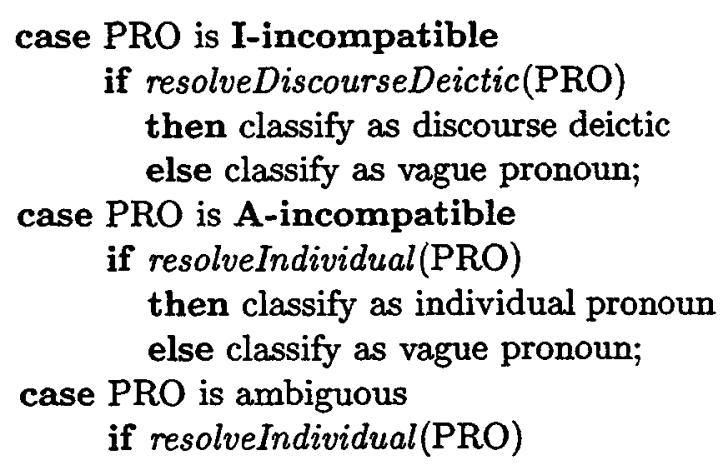

then classify as individual pronoun else if resolveDiscourseDeictic(PRO) then classify as discourse deictic else classify as vague pronoun;

The same algorithm is used for demonstratives, with the exception that the last two if constructions in the algorithm for pronouns are reversed reflecting the preference for demonstratives to be discourse deictics (Webber, 1991).

\section{Danish Data}

In this section I shortly describe Danish third person personal and possessive pronouns and demonstrative pronouns. The description focuses on the discourse deictic use of these pronouns based on occurrences in three Danish dialogue collections, Bysoc, ${ }^{7}$ SL and PID. My description is also based on (Allan et al., 1995). The third person singular personal and possessive pronouns can be found in table 2, while the third person plural personal and possessive pronouns can be found in table $3 .^{8}$

Den, det and de are also used as definite articles (the) and demonstrative determiners (this/that and these/those). In spoken language the demonstratives are always stressed. ${ }^{9}$ Den, det, de are demonstratives if followed by the adverbials her and $d e r$ in which case they correspond to the English this/these and that/those respectively. Furthermore, the demonstratives denne, dette (this) and disse (these) exist.

Feminine and masculine pronouns generally co-refer ${ }^{10}$ with persons, but can also refer to pets as in English. Common gender pronouns refer to common gender nouns which do not denote humans. Common gender nouns denoting humans are neutral as to the sex of the person they refer to. Thus the gender of

\footnotetext{
${ }^{7}$ The Bysoc corpus has been collected by researchers at Copenhagen University under "Projekt Bysociolingvistik" (Project Urban Sociolinguistics).

${ }^{8}$ The Danish reflexive pronouns are used differently than the English ones, see i.a. (Neville, 1998).

${ }^{9}$ Because I do not have access to phonetic information about the considered dialogues I cannot account for important phenomena such as intonation and prosody, see i.a. (Vallduvi and Engdahl, 1995).

${ }^{10}$ From now on I will simply write "refer to".
} 
Table 2: Third person singular pronouns

\begin{tabular}{|l|l|l|l|l|l|}
\hline \hline gender & subject & object & reflexive & possessive & pos.refl. \\
\hline feminine & hun she & hende her & sig herself & hendes hers & si $n / t / n e$ hers \\
\hline masculine & han he & ham him & sig himself & hans his & si-n/t/ne his \\
\hline common & den it & den it & sig itself & dens its & si $n / t / n e$ its \\
\hline neuter & det it & det it & sig itself & dets its & si-n/t/ne its \\
\hline \hline
\end{tabular}

Table 3: Third person plural pronouns

\begin{tabular}{|l|l|l|l|}
\hline \hline subject & object & reflexive & possessive \\
\hline de they & d'em them & sig themselves & deres their/ theirs \\
\hline \hline
\end{tabular}

the referring pronoun corresponds to the sex of the person the noun refers to.

Neuter gender pronouns are used to refer to neuter nouns. They can also refer to a few common person nouns in neuter gender, such as barn (child) and menneske (person) if the sex of the person is unknown or irrelevant (syntactic agreement). In case the sex is known or relevant, the appropriate feminine or masculine pronouns are used (semantic agreement). The two cases are illustrated in the following examples:

barnet var på millimeter så stort det skulle vere $i$ langden og $i$ hovedstørrelsen og...

(the child was precisely as high as it ought to be and its head was as big as it ought to and...)

så øh... jeg kunne gå ud for jeg havde mit barnebarn med pa tre et halvt år så..., kunne jeg jo bare holde ham $i$ händen

(so oh... I could leave because I was together with my three and half year old grandchild so..., I could just hold his hand)

Both den and det can refer to collective nouns. In this case the choice between the singular den or det and plural de depends on whether the speaker focuses on the collective meaning or on the individuals. Det and in few idiomatic expressions den are also used as expletives.
In Danish the most frequently used discourse deictic is det which corresponds to it, this or that. Other discourse deictics are det her (this) and det der (that). These two deictics can be used in most of the same contexts as det, although there seems to be a preference for using them to refer to several clauses. The neuter demonstrative dette (this) has also a discourse deictic use, but is mostly used in written language. I did not found any occurrences of it in the three dialogue collections.

As discourse deictic det refers to an infinitive or a clause, as it is the case in the following examples:

At ryge er farligt og det er også dyrt (Smoking is dangerous and it is also expensive)

A: Du skal tage en blodprøve

(You have to take a blood test)

B: Hvorfor det?

(Why is that?)

Det is also used as the subject complement of vere (be) and blive (become) in answers.

A: Blev du ferdig med opgaven?

(Were you done with the task?)

B: Ja, det blev jeg

(lit. Yes, that was I)

(Yes, I was)

Det refers to a verb phrase when it is used as the object complement for the verb have (have), gøre (do) and modal verbs as in 
Alle faldt, men det gjorde jeg ikke

(lit. All fell, but that did I not)

(All fell, but I did not)

Det refers to a clause in constructions with attitude verbs and other verbs which take clausal complements, such as synes (think), tro (believe) and vide (know), sige (say), häbe (hope):

\section{A: Det begynder snart at regne. \\ (It will soon begin to rain) \\ B: Det hảber jeg ikke \\ (lit. That hope I not) \\ (I hope not)}

In the latter three cases the pronoun det is often topicalized, i.e. it appears before the main verb, in the place that usually is occupied by the subject ${ }^{11}$.

Det can also refer to more clauses, or to something that can vaguely be inferred from the discourse.

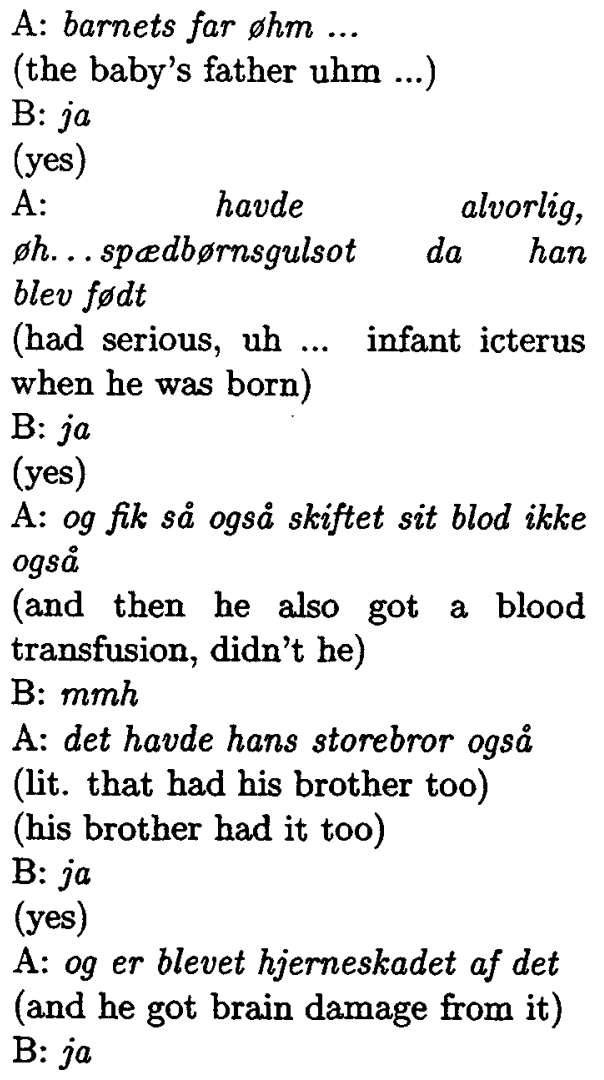

${ }^{11}$ This position is called fundamentfelt (actualization field) by (Diderichsen, 1984 1946). (yes)

A: altså jeg ved ikke om det er noget jeg skal, om det skal skrives nogen steder eller gøres noget ved (so I don't know whether it is something I should do, whether it should be written somewhere or something should be done)

In the above example the deictics in the last utterance do not refer to a single clause or predicate, but to the whole family history of icterus.

To conclude, Danish deictics are used in more contexts than the English ones. Especially noticeable is the Danish use of discourse deictics in cases where elliptical constructions are normal in English. ${ }^{12}$

\section{The Adapted ES99-algorithm}

On the basis of the deictics in the two Danish dialogue corpora, SL and PID I have established the following ${ }^{*} \mathrm{I}$ predicates for Danish:

- constructions where a pronoun is equated with an abstract object, e.g., $x$ er et forslag ( $\mathrm{x}$ is a suggestion)

- copula constructions with adjectives which can only be applied to abstract entities, such as $x$ er sandt ( $\mathrm{x}$ is true), $x$ er usandt ( $\mathrm{x}$ is untrue), $x$ er rigtigt ( $\mathrm{x}$ is correct)

- arguments of verbs which take S'complements, e.g., tro (believe), antage (assume), mene (think), sige (say)

- anaphoric referent in constructions such as $x$ er fordi $d u$ er holdt op med at ryge ( $\mathrm{X}$ is because you have stopped smoking) $x$ er pa grund af at du er gravid ( $\mathrm{x}$ is because you are pregnant)

- object of gøre (do)

- subject complement with vaere (be) and blive (become) in answers

\footnotetext{
${ }^{12}$ I have not included in the description cataphoric deictic pronouns.
} 
- object of have (have) if the verb was not used as a main verb in the previous clause

- object of modal verbs

The last four predicates are specific for Danish. I have assumed the following ${ }^{*} \mathrm{~A}$ predicates, which are mainly translations of the English ones:

- constructions where a pronominal referent is equated with a concrete individual referent, such as $x$ er en legemsdel ( $\mathrm{x}$ is a body part), $x$ er et barn ( $\mathrm{x}$ is a baby)

- copula constructions with adjectives which can only be applied to concrete entities, such as $x$ er rødt ( $\mathrm{x}$ is red)

- arguments of verbs describing physical contact/stimulation, which cannot be used anaphorically, e.g. spise $x$ (eat $\mathrm{x}$ ), drikke $x$ (drink $\mathrm{x}$ )

As Eckert and Strube notice for English, also in Danish there are cases where the contexts of an anaphor can allow both an individual NP and an abstract object. Some examples are copula constructions like $x$ er godt/darligt ( $\mathrm{x}$ is good/bad), and objects of verbs such as elske (love), hade (hate), foretrckke (prefer). To partially accomodate this, I have added the following condition to the algorithm: in the above cases the anaphor is classified as $\mathbf{A}^{*}$ incompatible unless the previous clause contains a raising adjective construction in which case it is considered I* incompatible. Consider the following two examples:

\section{Peter boede $i$ et rødt hus. Det hadede han.}

(Peter lived in a red house. He hated it.)

Det er dødsygt at sidde på et vaskeri. Det hader jeg.

(It is boring to be in a laundry. I hate it)

In the first example the algorithm chooses et rødt hus (a red house) as the antecedent of det, while in the second example the algorithm chooses at sidde pa et vaskeri (being in a laundry) instead of et vaskeri. There are cases, similar to the first example, where it is impossible, without a deeper analysis of the discourse to determine whether an anaphor refers to an individual NP or an abstract object.

In the test I have taken into account the metaphorical uses of verbs encoded in a semantic lexicon, the Danish SIMPLE lexicon (Pedersen and Nimb, 2000).

From the analysis of anaphors in the considered dialogue collections I found that many individual anaphors refer back to entities which have not been evoked in the immediately preceding utterances (SUs) and thus they would not be on the S-list (the entities which are not evoked in the current SU are removed from the list). Thus I have extended the scope of resolution for all individual anaphors except the neutral singular. If an antecedent to an individual NP cannot be resolved by looking at the actual S-list, the elements on the S-lists for the preceding SUs are considered. ${ }^{13}$

\section{Evaluation of the Algorithm}

I have applied the modified ES99-algorithm to three randomly selected SL dialogues $(6,305$ words) and to one of the dialogues between native Danes recorded in the PID collection $(5,367$ words $)$. It must be noted that in $\mathrm{my}$ test only one annotator (the author) identified dialogue acts, classified the anaphors in the dialogues, marked NPs and anaphor antecedents. In (Eckert and Strube, 1999a) these tasks have been accomplished by two annotators.

In dividing the three SL dialogues into discourse segments I have mainly used a partition made by two researchers at the University of Copenhagen in an independent project. The discrimination criteria were topic shift and a few linguistic clues. I have then ap-

\footnotetext{
${ }^{13}$ I have followed the cache model described in (Walker, 1998). In the present test it was necessary to go back maximally seven SUs to find an antecedent to an individual pronominal anaphor.
} 
plied the same discrimination criteria to the dialogue from the PID collection.

I have defined dialogue units syntactically following (Eckert and Strube, 1999a). ${ }^{14}$

Because it is not always possible to distinguish between den, det, de used as personal or demonstrative pronouns without having access to stress information, I have classified them as personal pronouns unless they are topicalized, or occur in syntactic constructions where demonstratives are normally used. The manual classification of pronouns and demonstratives in the four dialogues can be found in table 4 .

The results of the individual anaphora resolution algorithm can be found in table 5 , while the results of the discourse deictics resolution algorithm are given in table 6 .

The results obtained are better than those reported in (Eckert and Strube, 1999a), but I have used more background information than ES99 and extended the scope of resolution for individual anaphors (without this extension the precision of the individual resolution algorithm was of 64.5). Furthermore the Danish deictic det occurs in more contexts than the English it, this and that, thus there are more I* predicates in the Danish version of the algorithm than in the original one. The fact that only one annotator divided the dialogues into SUs may also have influenced the results.

The algorithm classifies anaphors and resolves some of them, thus there are two types of error, classification errors and resolution errors. Most of the instances of wrongly classified anaphors are due to the fact that the algorithm classifies vague anaphors as discourse deictics and then resolves the anaphor to a preceding predicate or clause. Few errors are due to the fact, already noticed by ES99, that the defined $I^{*}$ and $A^{*}$ predicates do not contain information about nominals referring to abstract objects. ${ }^{15}$ These errors resulted in most cases in resolution errors.

Some errors are due to the inability to find

\footnotetext{
${ }^{14}$ The dialogue collections have been tagged.

${ }^{15}$ The semantic lexicon I used did not contain the relevant nominals.
}

an individual NP antecedent to the pronoun det, when this refers generally to an NP of different gender ${ }^{16}$ and to wrongly resolved plural pronouns with complex NP antecedents or with no antecedent. Correctly classified, but wrongly resolved discourse deictics are, i.a., due to the fact that I did not mark in any particular way parenthetical utterances. The latter kind of errors are chaining errors. In table 7 the occurrences of each type of error are reported.

\section{Concluding Remarks}

The adapted ES99-algorithm has been tested on two kinds of dialogue, that have been classified by one annotator. Although the types of dialogue in the Danish test is quite different from that used by ES99, the results reported in the previous section (6) indicate that the algorithm performs as well for Danish as for English. Because the use of Danish pronouns, especially those referring to abstract objects, is different from the English one, these results provide an interesting evaluation of the algorithm.

As noticed by ES99, adding more lexical knowledge to the algorithm could improve its performance. I also believe that the contexts of abstract anaphors should be studied in more dialogues, and that more attention should be given to the connection between discourse deictics and the relations that link pieces of discourse to each other (Webber, 1991; Fraurud, 1992; Asher, 1993; Kehler, 1997).

Further work will thus consist in analyzing the occurrences of discourse deictics in both written texts and dialogues and paying additional attention to the relations linking pieces of discourse to each other (i.a. (Hobbs, 1979; Mann and Thompson, 1987; Polanyi, 1988)

\footnotetext{
${ }^{16}$ The use of especially generic plural pronouns in Swedish is discussed in (Fraurud, 1992).
} 
Table 4: Classification of Pronouns and Demonstratives

\begin{tabular}{|c|c|c|c|c|c|}
\hline & A5 & AA10 & AA11 & TR3 & $\sum$ \\
\hline Individual Pro & 39 & 43 & 34 & 51 & 167 \\
\hline Discourse DDeictics Pro & 25 & 16 & 17 & 34 & 92 \\
\hline Vague Pro & 4 & 6 & 0 & 2 & 12 \\
\hline Inferrable Evoked & 1 & 0 & 0 & 2 & 3 \\
\hline Individual Dem & 1 & 5 & 0 & 4 & 10 \\
\hline Discourse Deictics Dem & 27 & 20 & 19 & 28 & 94 \\
\hline Vague Dem & 2 & 5 & 3 & 3 & 13 \\
\hline
\end{tabular}

Table 5: Results of the Individual Anaphora Resolution Algorithm

\begin{tabular}{|c|c|c|c|c|c|}
\hline \hline & A5 & AA10 & AA11 & TR1 & $\sum$ \\
\hline No. resolved correctly & 31 & 40 & 23 & 40 & 134 \\
\hline No. of Individual Pro & 41 & 48 & 34 & 57 & 180 \\
\hline Precision & 0.756 & 0.833 & 0.676 & 0.701 & 0.744 \\
\hline
\end{tabular}

Table 6: Results of the Discourse Deictics Resolution Algorithm

\begin{tabular}{|c|c|c|c|c|c|}
\hline \hline & A5 & AA10 & AA11 & TR1 & $\sum$ \\
\hline No. resolved correctly & 43 & 25 & 33 & 49 & 147 \\
\hline No. of Discourse Deictics & 58 & 47 & 39 & 67 & 211 \\
\hline Precision & 0.741 & 0.489 & 0.846 & 0.716 & 0.696 \\
\hline \hline
\end{tabular}

Table 7: Wrongly resolved anaphors

\begin{tabular}{|l|c|}
\hline DD-vague & 10 \\
\hline wrongly resolved plural & 13 \\
\hline generic det & 7 \\
\hline abstract nominals & 5 \\
\hline individual anaphora instead of DD (\% abstract nominals) & 6 \\
\hline wrongly resolved DD & 28 \\
\hline wrongly resolved individual anaphora (singular) & 2 \\
\hline chaining errors & 39 \\
\hline \hline
\end{tabular}




\section{References}

Robin Allan, Philip Holmes, and Tom LundskærNielsen. 1995. Danish - A Comprehensive Grammar. Routledge, London.

Nicholas Asher. 1993. Reference to Abstract Objects in Discourse, volume 50 of Studies in Linguistics and Philosophy. Kluwer Academic Publishers, Dordrecht, the Netherlands.

D. Byron and A. Stent. 1998. A Preliminary Model of Centering in Dialog. In Proceedings of the 36th Annual Meeting, volume II, pages 1475-1477. Association for Computational Linguistics.

Paul Diderichsen. 1984-1946. Elementar Dansk Grammatik. Gyldendal, Copenhagen.

Miriam Eckert and Michael Strube. 1999a. Dialogue Acts, Synchronising Units and Anaphora Resolution. In Jan van Kuppevelt, Robert van Leusen, Robert van Rooy, and Henk Zeevat, editors, Amstelogue'99 Proceedings - Workshop on the Semantics and Pragmatics of Dialogue.

Miriam Eckert and Michael Strube. 1999b. Resolving Discourse Deictic Anaphora in Dialogues. In Proceedings of the 9th Conference of the European Chapter of the Association of Computational Linguistics, pages 37-44.

Kari Fraurud. 1992. Processing Noun Phrases in Natural Discourse. Department of Linguistics Stockholm University.

Barbara Grosz and Candace Sidner. 1986. Attention, Intentions, and the Structure of Discourse. Computational Linguistics, 12(3):175-284.

Barbara Grosz, Aravind K. Joshi, and Scott Weinstein. 1995. Centering:A Framework for Modeling the Local Coherence of Discourse. Computational Linguistics, 21(2):203-225.

Jerry R. Hobbs. 1979. Coherence and Coreference. Cognitive Science, 3(1):67-90.

Megumi Kameyama. 1998. Intrasentential centering: A case study. In Marilyn A. Walker, Aravind K. Joshi, and Ellen F Prince, editors, Centering Theory in Discourse, pages 89-112. Oxford University Press.

Andrew Kehler. 1997. Current Theories of Centering for Pronoun Interpretation: A critical Evaluation. Computational Linguistics, $23(3): 467-475$.

William C. Mann and Sandra A. Thompson. 1987. Rhetorical Structure Theory: Description and Construction of Text Structures.
In Gerard Kempen, editor, Natural Language Generation, number 135 in NATO ASI, pages 85-95. Martinus Nijhoff Publishers.

Costanza Navarretta. 2000. Centering-based Anaphora Resolution in Danish. In Petr Sojka, Ivan Kopecek, and Karel Pala, editors, Proceedings of the Third International Workshop on Text, Speech, Dialogue - TSD 2000, pages 345-350, Brno, Czech Republic.

Anne Neville. 1998. Subject-orientedness and Exempt Anaphors. In Proceedings of the Xth Conference of Nordic and General Linguistics University of Iceland, Reykjavik.

Bolette S. Pedersen and Sanni Nimb. 2000. Semantic Encoding of Danish Verbs in SIMPLE Adapting a verb-framed model to a satelliteframed language. In Proceeding from Second International Conference on Language Resources and Evaluation - LREC 2000, Athens.

Livia Polanyi. 1988. A Formal Model of the Structure of Discourse. Journal of Pragmatics, 12(5/6):601-638.

Ellen F. Prince. 1981. Toward a taxonomy of given-new information. In Peter Cole, editor, Radical Pragmatics, pages 223-255. Academic Press.

Michael Strube and Udo Hahn. 1996. Functional Centering. In Proceedings of the 34th Annual Meeting, pages 270-277. Association for Computational Linguistics.

Michael Strube and Udo Hahn. 1999. Functional Centering - Grounding Referential Coherence in Information Structure. Computational Linguistics, 25(3):309-344.

Michael Strube. 1998. Never Look Back: An Alternative to Centering. In Proceedings of the 36th Annual Meeting, volume II, pages 12511257. Association for Computational Linguistics.

Enric Vallduvi and Elisabet Engdahl. 1995. The linguistic realization of information packaging. Linguistics, 34(3):459-519.

Marilyn A. Walker. 1998. Centering, Anaphora Resolution, and Discourse Structure. In Marilyn A. Walker, Aravind K. Joshi, and Ellen F. Prince, editors, Centering Theory in Discourse. Oxford University Press.

Bonnie L. Webber. 1991. Structure and Ostension in the Interpretation of Discourse Deixis. Natural Language and Cognitive Processes, 6(2):107-135. 